\title{
Polymorphism and melt crystallisation of racemic betaxolol, a $\beta$-adrenergic antagonist drug
}

\author{
Teresa M. R. Maria • Ricardo A. E. Castro • M. Ramos Silva • \\ M. Luísa Ramos • Licínia L. G. Justino $\cdot$ Hugh D. Burrows • \\ João Canotilho $\cdot$ M. Ermelinda S. Eusébio
}

Received: 4 June 2012/ Accepted: 12 October 2012/Published online: 20 November 2012

(C) Akadémiai Kiadó, Budapest, Hungary 2012

\begin{abstract}
We report the polymorphic behaviour, in melt cooling experiments, of racemic betaxolol, a low aqueous solubility selective $\beta_{1}$-adrenergic antagonist drug with a flexible molecular structure. A multidisciplinary approach is employed, using thermal analysis (differential scanning calorimetry, polarised light thermomicroscopy), spectroscopic methods (infrared spectroscopy, magic angle spinning ${ }^{1} \mathrm{H} \mathrm{NMR}$ ) and $\mathrm{X}$-ray powder diffraction. A glass phase is obtained, $T_{\mathrm{g}} \sim-10^{\circ} \mathrm{C}$, on cooling the melt, unless the cooling rate is $\leq 0.5^{\circ} \mathrm{C} \min ^{-1}$, while a new metastable form, polymorph II, $T_{\text {fus }}=33{ }^{\circ} \mathrm{C}$, is generated in subsequent heating runs in a two step process. Although either partial crystallisation from the melt in the first step or the formation of an intermediate, metastable, low ordered phase may explain these observations, our results favour the second hypothesis. The stable polymorph I, $T_{\text {fus }}=69^{\circ} \mathrm{C}$, which crystallizes on further heating after form II melting,
\end{abstract}

T. M. R. Maria (凹) - M. L. Ramos - L. L. G. Justino ·

H. D. Burrows · M. E. S. Eusébio ( $\square)$

CQC, Department of Chemistry, University of Coimbra,

Rua Larga, 3004-535 Coimbra, Portugal

e-mail: troseiro@ci.uc.pt

M. E. S. Eusébio

e-mail: quierme@ci.uc.pt

R. A. E. Castro · J. Canotilho

CEF, Faculty of Pharmacy, University of Coimbra,

3000-548 Coimbra, Portugal

\section{R. Silva}

CEMDRX, Department of Physics, University of Coimbra, 3004-516 Coimbra, Portugal

M. L. Ramos - L. L. G. Justino

Centre for Neuroscience and Cell Biology, University

of Coimbra, 3004-517 Coimbra, Portugal has also been obtained either from polymorph II or from the molten phase, on standing at $25^{\circ} \mathrm{C}$. The racemic betaxolol crystalline phases are found to exhibit some degree of disorder.

Keywords Betaxolol - Phase transition - Melt crystallisation · Polymorphism · Disordered crystal

\section{Introduction}

Polymorphism, the ability of a compound to present different crystalline phases with different molecular arrangements and/or conformations is a common phenomenon among active pharmaceutical ingredients, APIs [1]. Different polymorphs tend to have distinct properties as discussed by Aguiar and coworkers in their pioneer studies on the effect of polymorphism on the dissolution rate and on the oral bioavailability of chloramphenicol palmitate $[2,3]$. The recognition of the impact of polymorphism at the different stages of a drug product life cycle makes the evaluation and characterisation of polymorphic forms of drugs an essential task [4-9], and, as a consequence, drug polymorphism has been the object of major academic and industrial attention [10-13].

Betaxolol, Scheme 1 , is a selective $\beta_{1}$-adrenergic antagonist drug which finds broad application in medical practice, e.g. in the treatment of arterial and intraocular hypertension, coronary artery diseases and chronic cardiovascular diseases $[14,15]$. Betaxolol molecule has an isopropyl-amino-2propanol group attached to an aromatic ring, a feature it shares with other $\beta$-blockers (e.g. pindolol, propranolol, atenolol). This ring is also para-substituted by a 2-(cyclopropylmethoxy)ethyl group. As a consequence, different kinds of intermolecular hydrogen bond interactions may be 


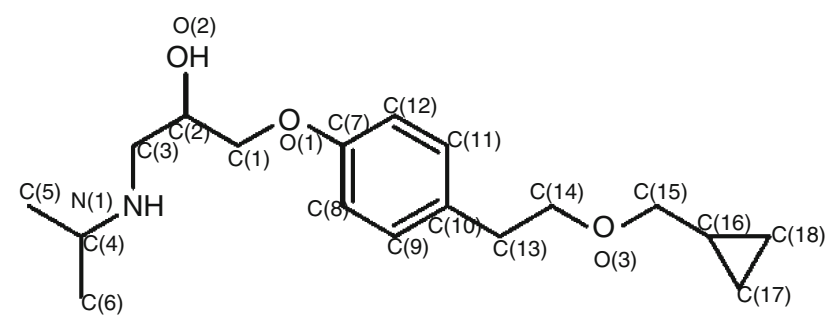

Scheme 1 Molecular structure of betaxolol, $(R, S)-1-\{p$-[2-(cyclopropylmethoxy) ethyl] phenoxy $\}$-3-isopropylamino-2-propanol

envisaged in a supramolecular assembly involving the hydroxyl, the amine and/or the ether groups. In addition, the betaxolol molecule displays considerable conformational flexibility. Taking these molecular characteristics into account, different polymorphic forms may be anticipated, either through packing or conformational effects [16]. One betaxolol crystalline structure has already been identified [17] in single crystals obtained from a methanol:water (20:80 $\mathrm{v} / \mathrm{v})$ mixture. In this solid form, some degree of disorder is observed. Although the methylethylamino head and the central planar group are perfectly ordered, the cyclopropylmethoxy group adopts two distinct conformations, with roughly $50 \%$ occupation of each. The uncertainty of the atomic positions in this part of the molecule implies that intermediate conformations may exist in the crystal.

Betaxolol bioavailability is solubility limited [18, 19]. Hot-melt methods, widely used in the food and polymer industries, are gaining increasing interest in pharmaceutical formulation development as a green, solvent free methodology to enhance dissolution rates of poorly water soluble drugs $[20,21]$. The relatively low melting temperature of betaxolol makes it a good candidate for this type of technology. As an initial step in the development of effective new formulations, a detailed assessment of the polymorphism of the pure API, and particularly of its polymorphic behaviour in melt cooling experiments is essential.

We report a study of the polymorphism of racemic betaxolol using melt cooling as the means to generate solid specimens. A multidisciplinary approach has been employed, using thermal analysis [differential scanning calorimetry (DSC) and polarised light thermomicroscopy (PLTM)], spectroscopic methods [infrared and magic angle spinning (MAS) ${ }^{1} \mathrm{H}$ nuclear magnetic resonance spectroscopy (NMR)] and X-ray powder diffraction (XRPD).

\section{Experimental}

Materials

Betaxolol was prepared by neutralisation of an aqueous solution of the corresponding betaxolol hydrochloride supplied by Capsifar Lda (purity specification of $99.68 \mathrm{~mol} \%$ ), followed by methylene chloride extraction. The solvent was removed in a rotary vacuum evaporator. Purity of the sample, 99.9 mol.\%, was determined by HPLC using a Gilson system with spectrophotometric detection at $\lambda=277 \mathrm{~nm}$ (Waters Spherisorb S5 ODS2 column, $4.6 \mathrm{~mm} \times 250 \mathrm{~mm} \times 5 \mu \mathrm{m}$; isocratic elution, mobile phase acetonitrile/phosphate buffer $0.025 \mathrm{M}(70 / 30, \mathrm{v} / \mathrm{v})$, $\left.\mathrm{pH}=4.5, T=24{ }^{\circ} \mathrm{C} ; 1.5 \mathrm{~mL} \min ^{-1}, p=197-203 \mathrm{psi}\right)$.

Crystallisation from solutions

Crystallisation from solution was carried out by slow evaporation of the solvent at room temperature. Apolar solvents ( $n$-hexane, dichloromethane), polar aprotic solvents (ethyl ether, ethyl acetate) and polar protic ones (methanol, methanol:water, 20:80 v/v) were used.

\section{Differential scanning calorimetry (DSC)}

A Perkin Elmer Pyris 1 DSC, a power compensation calorimeter, with helium purge, $20 \mathrm{~mL} \mathrm{~min}^{-1}$, and a liquid nitrogen Cryofill cooling unit was employed. Preliminary DSC experiments were carried out in the temperature range between $T=-170$ and $80{ }^{\circ} \mathrm{C}$ at $10^{\circ} \mathrm{C} \min ^{-1}$. As no thermal events were detected below $-20{ }^{\circ} \mathrm{C}$ a detailed study comprising heating/cooling cycles in the temperature range between -30 and $80^{\circ} \mathrm{C}$ was carried out. Perkin Elmer $40 \mu \mathrm{L}$ aluminium pans suitable for volatile substances were used. Temperature calibration was performed using cyclohexane (Merck, for gas-chromatography), $T_{\text {fus }}=(6.66 \pm 0.04){ }^{\circ} \mathrm{C}$, $T_{\text {trs }}=(-86.9 \pm 0.02){ }^{\circ} \mathrm{C}$; benzophenone (Mettler Toledo Calibration substance, $\left.T_{\text {fus }}=(48.1 \pm 0.2){ }^{\circ} \mathrm{C}\right)$ and biphenyl (CRM, LGC 2610), $T_{\text {fus }}=68.93{ }^{\circ} \mathrm{C}$ [22-24]. Biphenyl, $\Delta_{\text {trs }} H=(18.574 \pm 4) \mathrm{J} \mathrm{mol}^{-1}$, was used for enthalpy calibration [24].

Polarised light thermal microscopy (PLTM)

A DSC600 hotstage Linkam system was used with a Leica DMRB microscope and a Sony CCD-IRIS/RGB video camera. A $7 \mathrm{~mm}$ diameter glass cell was used. The images were obtained by combined use of polarised light and wave compensators, with $200 \times$ magnification. Real Time Video Measurement System software by Linkam was used for image analysis [25]. Biphenyl and benzophenone were used to confirm temperature accuracy [22, 24].

Infrared spectroscopy

Spectra were collected using $\mathrm{CaF}_{2}$ windows mounted in a Graseby Specac cell using liquid nitrogen as cooling agent. 
The spectra were recorded on a Thermo Nicolet IR 300 spectrometer, with $1 \mathrm{~cm}^{-1}$ spectral resolution.

X-ray powder diffraction (XRPD)

Glass capillaries with $0.5 \mathrm{~mm}$ diameter were filled with the powdered specimens. The samples were mounted on an ENRAF-NONIUS powder diffractometer (equipped with a CPS120 detector by INEL) and data were collected for 30 min using Debye-Scherrer geometry. Monochromatized $\mathrm{Cu} \mathrm{K} \alpha_{1}$ radiation was used $(\lambda=1.5406 \AA)$. Silicon was chosen as an external calibrant. Samples were heated by a hot nitrogen gas stream (Oxford Cryosystems, series 600), at an approximate rate of $6{ }^{\circ} \mathrm{C} \mathrm{min}^{-1}$.

Nuclear magnetic resonance spectroscopy (NMR)

The ${ }^{1} \mathrm{H}$ NMR spectrum of the betaxolol sample dissolved in methanol- $d_{4}$ was recorded on a Varian VNMRS $600 \mathrm{MHz}$ spectrometer at $599.72 \mathrm{MHz}$. The MAS [26-29] ${ }^{1} \mathrm{H}$ NMR spectra of neat betaxolol samples were obtained on the same spectrometer, at variable temperatures, with a PFG nano gHX probe at a spinning speed of $4 \mathrm{kHz}$ in a $4 \mathrm{~mm}$ rotor, using the methyl signal of methanol as external reference $(\delta 3.31 \mathrm{ppm})$.

\section{Results and discussion}

Thermal analysis

Solid betaxolol, obtained by the procedures described in both the materials and solution crystallisation parts of the experimental section, has been identified by XRPD as the crystalline phase isolated by Canotilho et al. [17], hereafter termed polymorph I. The same polymorph was obtained upon crystallisation from all the solvents tested.

A typical DSC heating curve of polymorph $\mathrm{I}$, at a scanning rate $\beta=10^{\circ} \mathrm{C} \min ^{-1}$, is shown in Fig. 1. Only one endothermic transition is observed. This corresponds to the fusion process, as confirmed by PLTM experiments: $T_{\text {fus }}=(69.0 \pm 0.3){ }^{\circ} \mathrm{C}, \quad \Delta_{\text {fus }} H=(47.3 \pm 1.6) \mathrm{kJ} \mathrm{mol}^{-1}$. The numerical values presented are the mean of $n=12$ independent experiments, with the uncertainty expressed as one standard deviation.

No crystallisation was observed on cooling molten betaxolol at rates ranging from -25 to $-2{ }^{\circ} \mathrm{C} \mathrm{min}^{-1}$, with the only thermal event registered being a glass transition $\left(T_{\mathrm{g}} \sim-9{ }^{\circ} \mathrm{C}\right.$, for a scanning rate $\beta=-10^{\circ} \mathrm{C} \mathrm{min}^{-1}$, Fig. 2, curve 1). On heating the glass phase, Fig. 2, curve 2 , devitrification occurs at around $-10{ }^{\circ} \mathrm{C}\left(\beta=10{ }^{\circ} \mathrm{C} \mathrm{min}^{-1}\right)$ followed by two exothermic events: cold crystallisation at about $0{ }^{\circ} \mathrm{C}$ and another exothermic process at about $10{ }^{\circ} \mathrm{C}$. It is interesting to note that these two distinct exothermic (a)

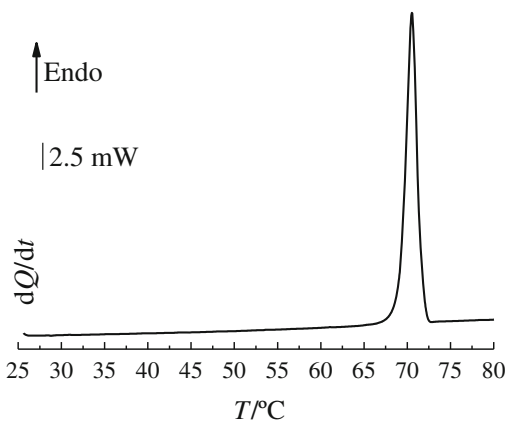

(b)

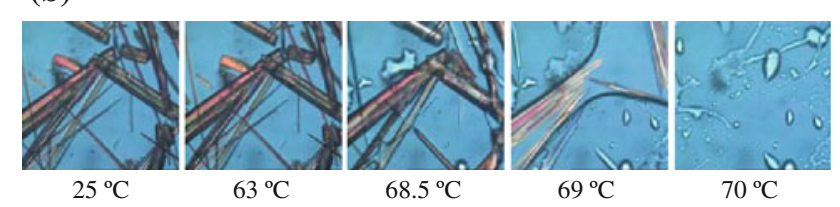

Fig. 1 Betaxolol polymorph I heating run, $\beta=10{ }^{\circ} \mathrm{C} \min ^{-1}$ a DSC; $m=2.03 \mathrm{mg}$. b Polarised light thermal microscopy. Magnification $\times 200$

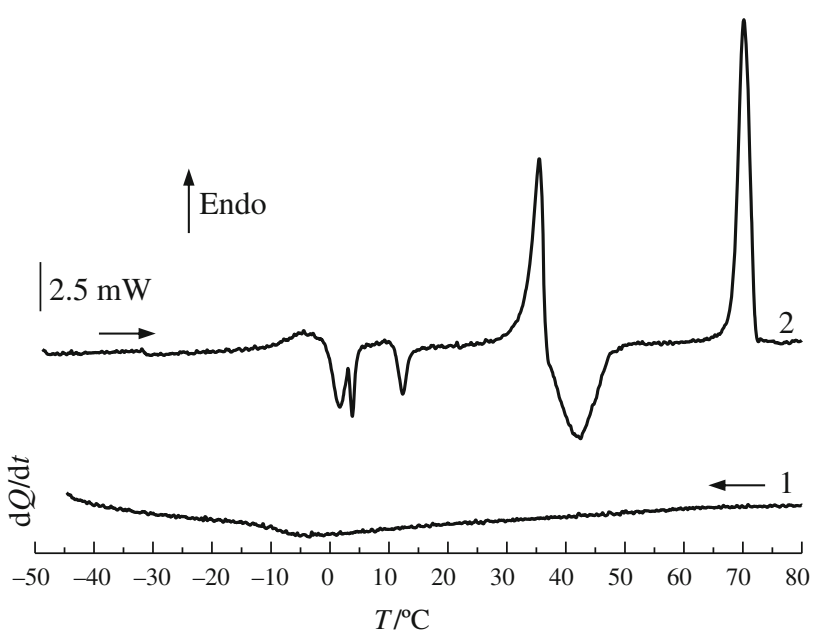

Fig. 2 DSC curves of betaxolol. 1 Cooling the melt; 2 heating run following (1); $\beta=|10|^{\circ} \mathrm{C} \min ^{-1} ; m=1.86 \mathrm{mg}$

events are observed in all experiments, even when the heating rate is changed (from 2 to $25^{\circ} \mathrm{C} \mathrm{min}-1$ ). At $T \sim 33{ }^{\circ} \mathrm{C}$ the fusion of a metastable phase is observed, and is followed by a crystallisation process giving rise to polymorph I. At about $69^{\circ} \mathrm{C}$ the fusion of polymorph I takes place.

The formation of ordered crystalline structures involves nucleation and growth, which are kinetically controlled processes, and as a consequence may result in melt supercooling [30]. As the temperature decreases, there is a sharp viscosity increase, leading to restricted molecular motion which may prevent the formation of ordered crystalline structures. This is expected to be particularly relevant for flexible molecule compounds such as betaxolol, and as a consequence the formation of an amorphous phase in not surprising. 
A cooling rate of $-0.5{ }^{\circ} \mathrm{C} \mathrm{min}-1$ is low enough to allow the nucleation and growth of an ordered betaxolol structure. For instance, in the cooling experiment shown in Fig. 3, curve 3 , crystallisation occurs at about $-5{ }^{\circ} \mathrm{C}$. In the subsequent heating run, $\left(\beta=10^{\circ} \mathrm{C} \min ^{-1}\right)$, Fig. 3 , curve 4 , as expected, devitrification is not observed, and, therefore, the
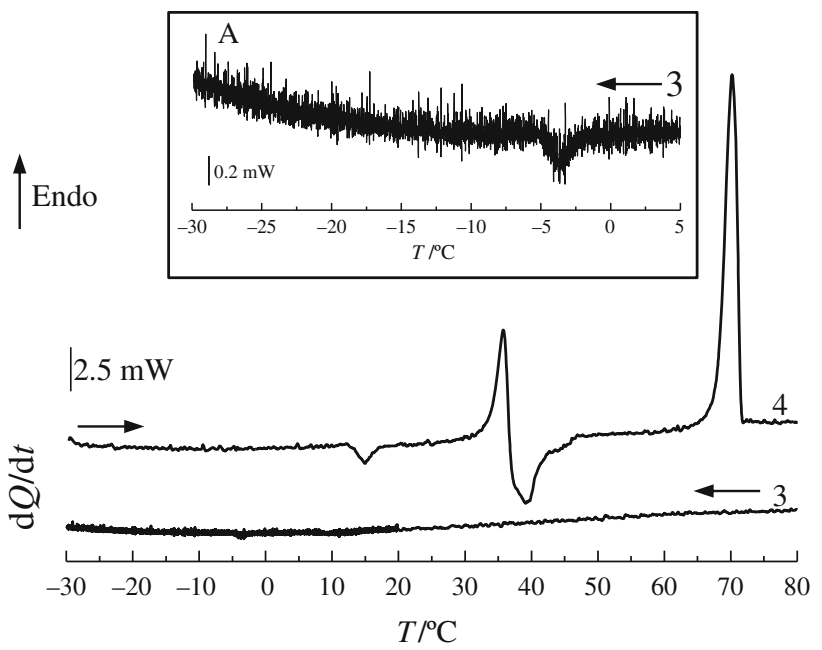

Fig. 3 DSC curves of betaxolol: 3 Cooling the melt $(\beta=$ $-10{ }^{\circ} \mathrm{C} \mathrm{min}{ }^{-1}$, for $80{ }^{\circ} \mathrm{C} \geq T \geq 20{ }^{\circ} \mathrm{C} ; \quad \beta=-0.5{ }^{\circ} \mathrm{C} \mathrm{min}{ }^{-1}$, for $20{ }^{\circ} \mathrm{C} \geq T \geq-30{ }^{\circ} \mathrm{C}$ ); 4 heating run following (3) $\beta=10{ }^{\circ} \mathrm{C} \min ^{-1}$; $m=1.84 \mathrm{mg}$. $A$ Inset of the cooling step at $\beta=-0.5{ }^{\circ} \mathrm{C} \mathrm{min}^{-1}$ cold crystallisation is absent. However, the exothermic transition at about $10{ }^{\circ} \mathrm{C}$ still occurs.

A thermal cycle similar to that reported in Fig. 3 was followed by polarised light thermomicroscopy, and some selected PLTM images are presented in Fig. 4. The light intensity signal recorded in the same experiment is shown as a function of temperature in Fig. 5. The use of light intensity profiles obtained in PLTM experiments has been found to be useful to verify thermal events $[12,31]$. Cooling the molten compound at $\beta=-0.5{ }^{\circ} \mathrm{C} \mathrm{min}{ }^{-1}$ gives rise to the formation of a weakly birefringent solid phase at about $-5{ }^{\circ} \mathrm{C}$, Fig. 4a. This event produces a change in the light intensity as clearly seen in Fig. 5, curve a. In the subsequent heating run, at $10{ }^{\circ} \mathrm{C} \mathrm{min}-1$, Fig. $4 \mathrm{~b}$ and curve $b$ in Fig. 5, no changes are observed until about $10{ }^{\circ} \mathrm{C}$, where a clear sample modification takes place, as illustrated by the images recorded at 9 and $14{ }^{\circ} \mathrm{C}$ (before and after the event, respectively), Fig. $4 \mathrm{~b}$. Melting at $\sim 33{ }^{\circ} \mathrm{C}$, followed by crystallisation of polymorph I, which melts around $69{ }^{\circ} \mathrm{C}$, are the other events observed.

From these experiments a new metastable polymorph, betaxolol form II, $T_{\text {fus }}=(33.4 \pm 0.5){ }^{\circ} \mathrm{C}, n=7$, is clearly identified. Polymorph II is obtained from the liquid in a two step process. The observation of two exothermic transitions before melting at $T \sim 33{ }^{\circ} \mathrm{C}$ may arise from partial liquid crystallisation after devitrification or in the cooling runs at
Fig. 4 PLTM images. a Cooling molten betaxolol to $-12{ }^{\circ} \mathrm{C}$, at $\beta=-0.5^{\circ} \mathrm{C} \min ^{-1} ; \mathbf{b}$ PLTM images of the heating process performed after the cooling run reported in (a),

$\beta=10{ }^{\circ} \mathrm{C} \min ^{-1}$,

magnification $\times 200$ (a)

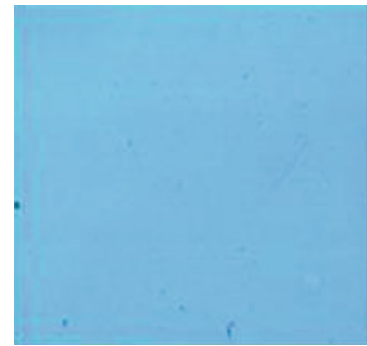

$0.5^{\circ} \mathrm{C}$

$-5^{\circ} \mathrm{C}$

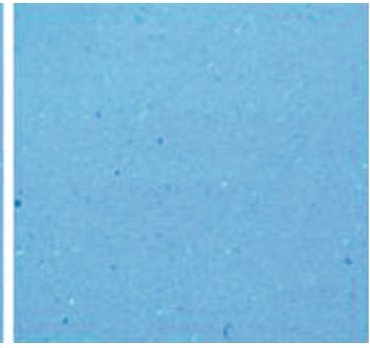

$-9{ }^{\circ} \mathrm{C}$ (b)

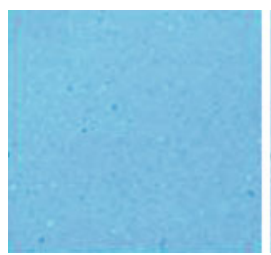

$9{ }^{\circ} \mathrm{C}$

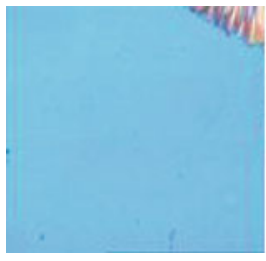

$37^{\circ} \mathrm{C}$

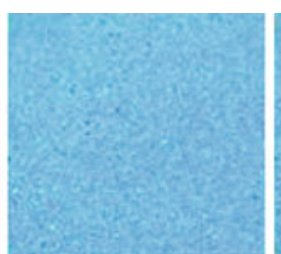

$14^{\circ} \mathrm{C}$

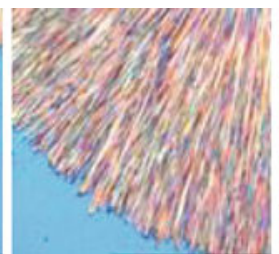

$40{ }^{\circ} \mathrm{C}$

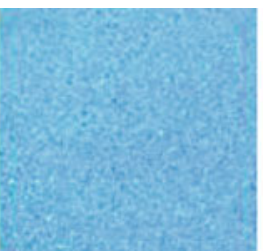

$34{ }^{\circ} \mathrm{C}$

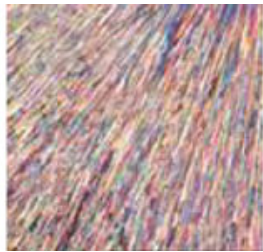

$69{ }^{\circ} \mathrm{C}$

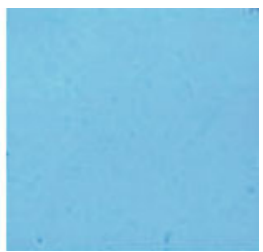

$36^{\circ} \mathrm{C}$

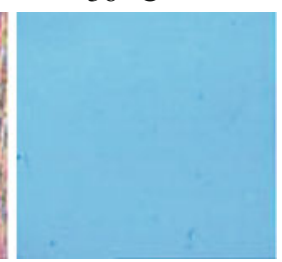

$71^{\circ} \mathrm{C}$ 


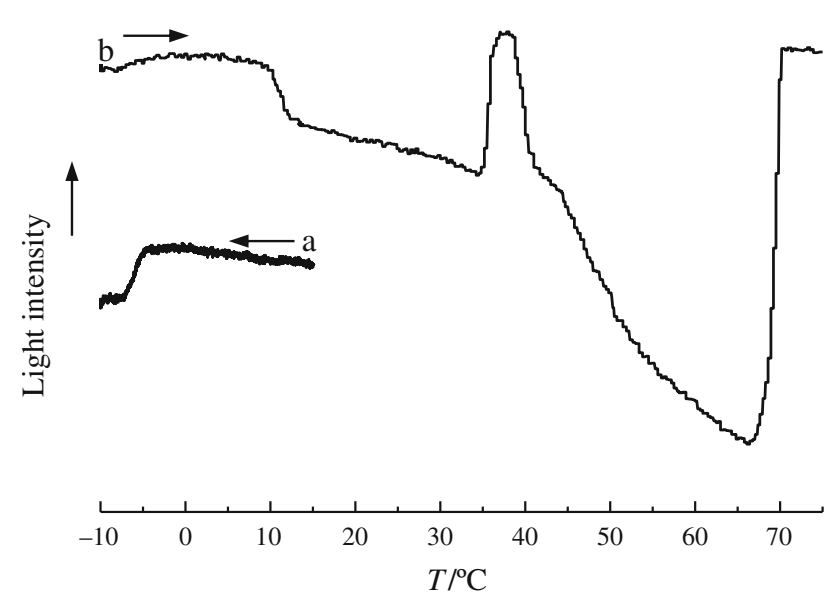

Fig. 5 Light intensity signal registered in the PLTM experiment shown in Fig. 4. $a$ Cooling molten betaxolol to $-12{ }^{\circ} \mathrm{C}$, at $\beta=-0.5^{\circ} \mathrm{C} \mathrm{min}{ }^{-1}$. $b$ Heating process performed after $(a), \beta=10^{\circ} \mathrm{C} \min ^{-1}$

low scanning rate, giving rise to polymorph II. The liquid crystallisation may be completed in the second exothermic event. However, although this interpretation cannot be discarded, the observation of both exothermic events, despite the use of different DSC experimental conditions, does not seem compatible with it. An alternative interpretation is that a low ordered intermediate metastable phase, form III, may be formed in the first crystallisation step, and the second exothermic event will then correspond to a solid III $\rightarrow$ solid II phase transition.

Both polymorphs I and II were also obtained in some melt cooling experiments carried out at $\beta=-0.5^{\circ} \mathrm{C} \mathrm{min}-1$. When annealed at $25{ }^{\circ} \mathrm{C}$, polymorph II gives rise to polymorph I, consistent with the monotropic relationship between these two forms.

Additional experiments were carried out to further characterise the molten phase behaviour at $25{ }^{\circ} \mathrm{C}$. Polymorph I or a mixture of forms I and II are obtained on standing, typically overnight.

\section{Infrared spectroscopy}

For infrared spectroscopic studies, the betaxolol sample was prepared by melting a small amount of substance dispersed between two $\mathrm{CaF}_{2}$ windows in an oven at $80{ }^{\circ} \mathrm{C}$. The windows were then mounted in a variable temperature Graseby Specac cell, cooled to $-30{ }^{\circ} \mathrm{C}$ and afterwards heated until fusion. The relevant differences observed in the spectra registered in the heating process correspond to the $\mathrm{N}-\mathrm{H}$ and $\mathrm{O}-\mathrm{H}$ stretching vibration zone and are presented in Fig. 6 for selected temperature values.

The spectrum shown at $60{ }^{\circ} \mathrm{C}$ matches that published by Canotilho and Castro [32] as expected if the same polymorphic form is obtained. In this polymorph, form I, the

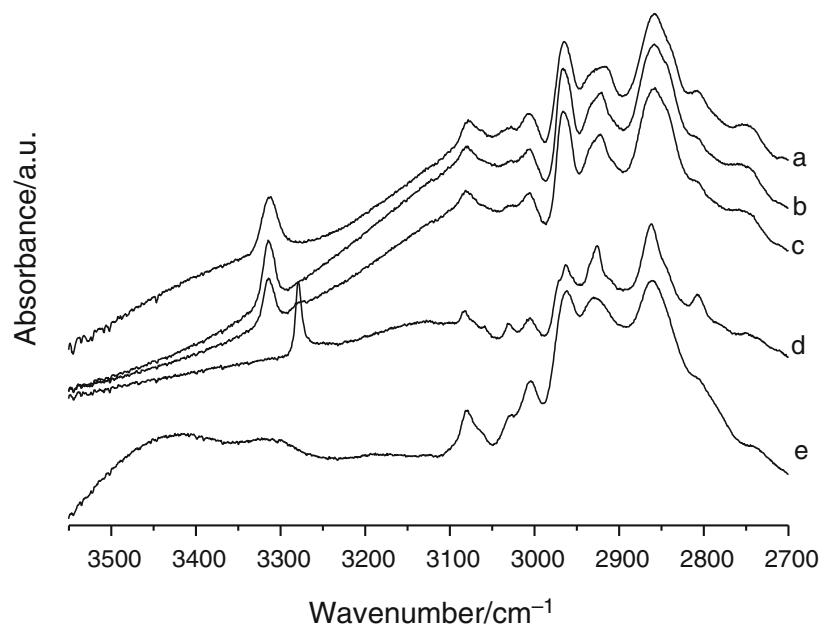

Fig. 6 Infrared spectra, 3,550-2,700 $\mathrm{cm}^{-1}$ range, collected in the heating process of a betaxolol sample prepared by cooling the molten compound, in the conditions specified in the text. $a T=-30{ }^{\circ} \mathrm{C}$, $b T=10^{\circ} \mathrm{C}, c T=35^{\circ}, d T=60{ }^{\circ} \mathrm{C}, e T=90^{\circ} \mathrm{C}$, liquid

molecules are joined together in ribbons along the $a$-axis by two types of intermolecular hydrogen bonds: in one of them the $\mathrm{N}-\mathrm{H}$ group acts as a donor to the hydroxyl oxygen, and in the other the nitrogen atom is the acceptor relative to the $\mathrm{OH}$ group. A $v_{\mathrm{N}-\mathrm{H}}$ stretching band centred at $3,278 \mathrm{~cm}^{-1}$ is observed in this polymorph. It is instructive to follow its evolution from $-30{ }^{\circ} \mathrm{C}$ until fusion.

The spectrum collected at $-30{ }^{\circ} \mathrm{C}$ shows significant differences relative to that of the liquid, and is very similar to the spectrum obtained at $10{ }^{\circ} \mathrm{C}$, indicating it is not likely to be that of a glass phase. At $-30{ }^{\circ} \mathrm{C}$ the $v_{\mathrm{N}-\mathrm{H}}$ band is centred at $3,314 \mathrm{~cm}^{-1}$. At $10{ }^{\circ} \mathrm{C}$, in a spectrum assigned to polymorph II, the $v_{\mathrm{N}-\mathrm{H}}$ band, although centred at the same wavenumber, becomes considerably narrower. This is consistent with an increase of order of the solid phase at $10{ }^{\circ} \mathrm{C}$ relative to the sample present at $-30{ }^{\circ} \mathrm{C}$, although it is not possible to distinguish between a phase transition from a more disordered phase to a less disordered one and crystallisation of residual liquid.

At $35{ }^{\circ} \mathrm{C}$, the transformation to polymorph I has already begun: in addition to the main $\mathrm{N}-\mathrm{H}$ stretching band at $3,314 \mathrm{~cm}^{-1}$, a small one appears at $\sim 3,278 \mathrm{~cm}^{-1}$. The displacement of $v_{\mathrm{N}-\mathrm{H}}$ band maximum towards lower wavenumbers $\left(\Delta v=-36 \mathrm{~cm}^{-1}\right)$ is consistent with an increase of the strength of the hydrogen bonds involving this group in polymorph I, when compared to the lower temperature samples.

\section{X-ray powder diffraction}

The diffractograms shown in Fig. 7 were obtained in a heating run $\left(\beta \sim 6{ }^{\circ} \mathrm{C} \mathrm{min}{ }^{-1}\right)$ performed on the amorphous phase, Fig. 7, curve a, which was generated by 


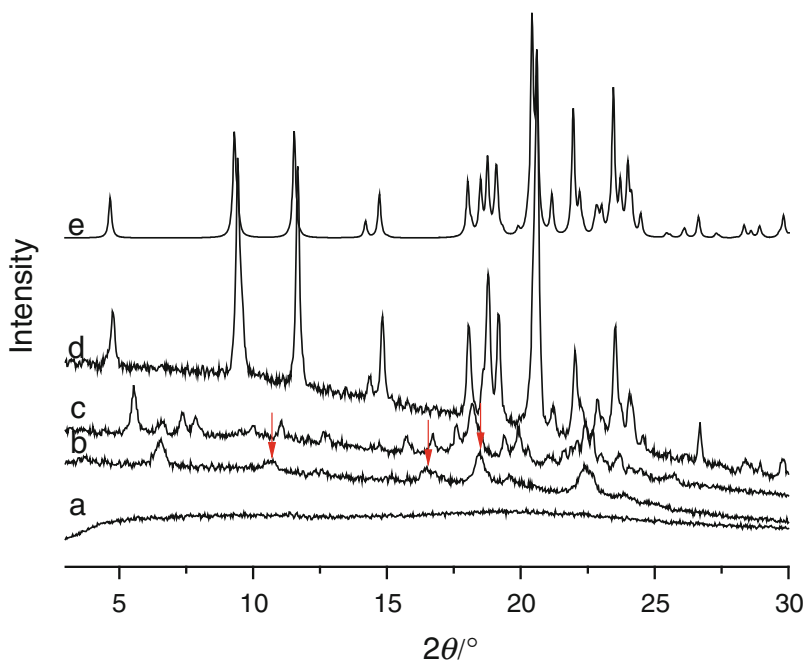

Fig. 7 Powder X-ray diffractograms obtained in a heating run of amorphous betaxolol, $\beta \sim 6{ }^{\circ} \mathrm{C} \mathrm{min}{ }^{-1}$ at $a T=-20{ }^{\circ} \mathrm{C}, b T=0{ }^{\circ} \mathrm{C}$, $c T=15^{\circ}, d T=42^{\circ} \mathrm{C}, e$ simulated for polymorph I [17]

quenching the molten sample contained in the capillary. The diffractogram at $0{ }^{\circ} \mathrm{C}$ (Fig. 7, curve b) shows a few broad peaks, some of which, $2 \theta=10.6,16.5$ and $18.5^{\circ}$, are not present in the diffractograms obtained at higher temperature and can be attributed to a low order phase. A less symmetrical, less disordered phase is formed on further heating (Fig. 7, curve c), and, finally, at $\sim 42{ }^{\circ} \mathrm{C}$ (Fig. 7, curve d), the diffractogram of polymorph $\mathrm{I}$ is observed (simulated powder X-ray diffractogram in Fig. 7, curve e, from single crystal data [17]). Although the heating rates for XRPD, DSC, FTIR and NMR are different, the diffractogram shown at $15{ }^{\circ} \mathrm{C}$ may be tentatively assigned to polymorph II, while there are hints of the existence of another polymorph, (form III ?).

\section{${ }^{1}$ H NMR spectroscopy}

Figure 8 shows the ${ }^{1} \mathrm{H}$ NMR spectrum of betaxolol in a methanol- $d_{4}$ solution. The assignment was based on the ${ }^{1} \mathrm{H}$ nuclear shielding constants calculated at the GIAO/B3LYP level for the DFT optimised geometry of the molecule [6-31G $(d, p)$ basis set; betaxolol molecular structure A in crystalline polymorph I [17] was used as the starting geometry].

The solid betaxolol sample was melted at $\sim 80{ }^{\circ} \mathrm{C}$ in an oven, inside the NMR rotor, and quenched to $-25^{\circ} \mathrm{C}$ in a cryostat. The first magic angle spinning (MAS NMR) experiment was carried out at $18{ }^{\circ} \mathrm{C}$, the lowest temperature attainable with the equipment.

Betaxolol polymorphs were studied using MAS NMR in the range of temperatures from 18 to $40{ }^{\circ} \mathrm{C}$, and the

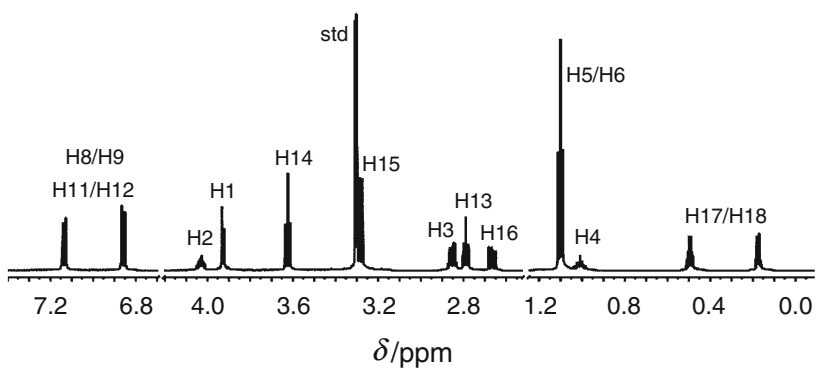

Fig. $8{ }^{1} \mathrm{H}$ NMR spectrum of a betaxolol solution in methanol- $d_{4}$ at $25^{\circ} \mathrm{C}$. The numbering system is identical to that in Scheme 1 and is based on the X-ray data in ref [17]

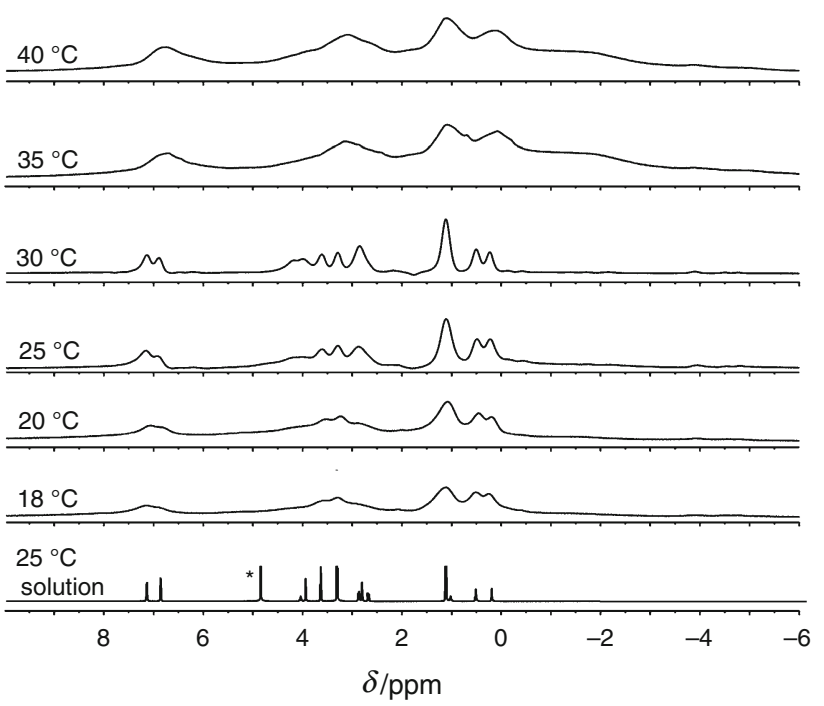

Fig. $9{ }^{1}$ H MAS NMR spectra of betaxolol at indicated temperatures and solution spectrum in methanol- $d_{4}$ (asterisk identifies the residual water signal). Chemical shifts are relative to TMS using methanol $(\delta 3.31 \mathrm{ppm})$ as external reference

recorded spectra are presented in Fig. 9. The solution spectrum is also included for comparison.

The ${ }^{1} \mathrm{H}$ spectrum at $18{ }^{\circ} \mathrm{C}$ (attributed to polymorph II) shows the same resonances as in the solution spectrum. However, it is strongly broadened due to residual magnetic dipolar couplings (and possibly, although less important, residual chemical shift anisotropy) which arises from the restricted motion of the molecules in this condensed phase. From 18 to $30{ }^{\circ} \mathrm{C}$, changes are observed in the relative intensities of the alkyl $\mathrm{CH}_{2}$ signals in the $2-4 \mathrm{ppm}$ region, suggesting some conformational rearrangement in the molecule and, thus, an increase in disorder. Between 25 and $30{ }^{\circ} \mathrm{C}$, the ${ }^{1} \mathrm{H}$ signals become narrower, as we approach the melting temperature $\left(33^{\circ} \mathrm{C}\right.$, as seen by DSC) of this metastable phase. The narrowing of the NMR signals is a consequence of a decrease in the residual magnetic dipolar couplings, which is compatible with a loss of 
organisation and increased flexibility of the system. At 35 and $40{ }^{\circ} \mathrm{C}$, where DSC and PLTM show crystallisation of the melt to form polymorph I, the NMR signals become broader again, compatible with a decrease in mobility, while new resonances are detected between 0 and $-3 \mathrm{ppm}$. The intensities of these additional resonances decrease with increasing spinning speeds, suggesting that they are related to anisotropic interactions. These additional signals, which are detected for polymorph I, but not with polymorph II, indicate that the former polymorph has a more ordered and rigid structure.

Also consistent with previous considerations, an upfield shift $(0.23 \mathrm{ppm})$ of the aromatic resonances is observed in the transition from polymorph II to polymorph I $\left(30-35^{\circ} \mathrm{C}\right)$. This is compatible with the recrystallisation process which occurs in the transition between the two polymorphs, since an upfield shift of the ${ }^{1} \mathrm{H}$ aromatic resonances suggests the formation of intermolecular interactions involving the $\pi$-rings, such as $\pi$-stacking (which diminish the electronic density on the rings, shielding the protons).

\section{Conclusions}

A complex polymorphic behaviour has been identified for racemic betaxolol, a selective $\beta_{1}$-adrenergic antagonist drug. In melt cooling experiments, unless the cooling rate is very slow $\left(\beta \leq-0.5^{\circ} \mathrm{C} \mathrm{min}-1\right)$, a glass phase is obtained, $T_{\mathrm{g}} \sim-10{ }^{\circ} \mathrm{C}\left(\beta=10^{\circ} \mathrm{C} \mathrm{min}^{-1}\right)$. This is not an uncommon observation for substances whose molecules exhibit high conformational flexibility [33]. Devitrification gives rise to a metastable solid form, polymorph II, $T_{\text {fus }}=33{ }^{\circ} \mathrm{C}$, in a two step process. Partial liquid crystallisation in the first step or the formation of an intermediate metastable low ordered phase may explain this observation, with the results favouring the second hypothesis. FTIR, XRPD and ${ }^{1} \mathrm{H}$ MAS NMR data point to some degree of disorder in these metastable phases. Disorder has already been observed in polymorph I, particularly related to the cyclopropylmethoxy group [17]. The stable polymorph I, $T_{\text {fus }}=69{ }^{\circ} \mathrm{C}$, was obtained occasionally on melt cooling experiments at $-0.5{ }^{\circ} \mathrm{C} \mathrm{min}{ }^{-1}$, at $25^{\circ} \mathrm{C}$ by overnight annealing either the molten phase or polymorph II, and on heating runs after form II fusion.

Acknowledgements The authors acknowledge the "Rede Nacional de RMN" for the spectrometer facilities, and Dr. Emeric Wasielewski for help in data acquisition. The Varian VNMRS $600 \mathrm{MHz}$ spectrometer is part of the National NMR Network and was purchased in the framework of the National Programme for Scientific Re-equipment, contract REDE/ 1517/RMN/2005, with funds from POCI 2010 (FEDER) and "Fundação para a Ciência e a Tecnologia" (FCT). L.L.G.J. acknowledges FCT for the postdoctoral grant SFRH/BPD/26415/2006.

\section{References}

1. Stahly GP. Diversity in single- and multiple-component crystals. The search for and prevalence of polymorphs and cocrystals. Cryst Growth Des. 2007;7:1007-26.

2. Aguiar AJ, Krc J, Kinkel AW, Samyn JC. Effect of polymorphism on absorption of chloramphenicol from chloramphenicol palmitate. J Pharm Sci. 1967;56:847-53.

3. Aguiar AJ, Zelmer JE. Dissolution behavior of polymorphs of chloramphenicol palmitate and mefenamic acid. J Pharm Sci. 1969;58:983-7.

4. Bernstein J. Polymorphism in molecular crystals. Oxford: Oxford Science Publications; 2002.

5. Brittain HG. Polymorphism in pharmaceutical solids. New York: Marcel Dekker, Inc.; 1999.

6. CDER, ANDAs: Pharmaceutical solid polymorphism. Center for Drug Evaluation and Research (CDER); 2007.

7. Hilfiker R. Polymorphism in the pharmaceutical industry. Weinheim: Wiley VCH; 2006.

8. ICH, Guidance for industry, Q6A specifications: test procedures and acceptance criteria for new drug substances and new drug products: chemical substances. Int Conf Harmonisation. 2000;65: 83041-63.

9. McCrone WC. Physics and chemistry of the organic solid state. In: Fox D, Labes MM, Weissberger A, editors. Polymorphism. New York: Wiley Interscience; 1965. p. 725-76.

10. Foces-Foces C, Victoria Roux M, Notario R, Segura M. Thermal behavior and polymorphism in medium-high temperature range of the sulfur containing amino acids L-cysteine and L-cystine. J Therm Anal Calorim. 2011;105:747-56.

11. Herman C, Leyssens T, Vermylen V, Halloin V, Haut B. A new approach for the estimation of the melting enthalpy of metastable crystalline compounds using differential scanning calorimetry Application to the two crystallographic forms of etiracetam. J Therm Anal Calorim. 2012;107:777-88.

12. Abu Bakar MR, Nagy ZK, Rielly CD. A combined approach of differential scanning calorimetry and hot-stage microscopy with image analysis in the investigation of sulfathiazole polymorphism. J Therm Anal Calorim. 2010;99:609-19.

13. Perlovich GL BS, Manin NG, Volkova TV, Tkachev VV, Polymorphism and solvatomorphism of bicalutamide. J Therm Anal Calorim. 2012. doi:10.1007/s10973-012-2540-y.

14. Melena J, Wood JPM, Osborne NN. Betaxolol, a beta(1)-adrenoceptor antagonist, has an affinity for $\mathrm{L}$-type $\mathrm{Ca}^{2+}$ channels. Eur J Pharmacol. 1999;378:317-22.

15. Suzuki J, Watanabe K, Tsuruoka T, Sueda S, Funada J, Kitakaze M, Sekiya M. Beneficial effects of betaxolol, a selective antagonist of beta-1 adrenoceptors, on exercise-induced myocardial ischemia in patients with coronary vasospasm. Int J Cardiol. 2003;91:227-32.

16. Nangia A. Conformational polymorphism in organic crystals. Acc Chem Res. 2008;41:595-604.

17. Canotilho J, Castro RAE, Rosado MTS, Silva MR, Beja AM, Paixao JA, Redinha JS. The structure of betaxolol from single crystal X-ray diffraction and natural bond orbital analysis. J Mol Struct. 2008;891:437-42.

18. Takagi T, Ramachandran C, Bermejo M, Yamashita S, Yu LX, Amidon GL. A provisional biopharmaceutical classification of the top 200 oral drug products in the United States, Great Britain, Spain, and Japan. Mol Pharm. 2006;3:631-43.

19. Meylan WM, Howard PH, Boethling RS. Improved method for estimating water solubility from octanol water partition coefficient. Environ Toxicol Chem. 1996;15:100-6.

20. Crowley MM, Zhang F, Repka MA, Thumma S, Upadhye SB, Battu SK, McGinity JW, Martin C. Pharmaceutical applications of hot-melt extrusion: part I. Drug Dev Ind Pharm. 2007;33: 909-26. 
21. Repka MA, Battu SK, Upadhye SB, Thumma S, Crowley MM, Zhang F, Martin C, McGinity JW. Pharmaceutical applications of hot-melt extrusion: part II. Drug Dev Ind Pharm. 2007;33:1043-57.

22. Chirico RD, Knipmeyer SE, Steele WV. Heat capacities, enthalpy increments, and derived thermodynamic functions for benzophenone between the temperatures $5 \mathrm{~K}$ and $440 \mathrm{~K}$. J Chem Thermodyn. 2002;34:1885-95.

23. Della Gatta G, Richardson MJ, Sarge SM, Stolen S. Standards, calibration, and guidelines in microcalorimetry-Part 2 Calibration standards for differential scanning calorimetry-(IUPAC technical report). Pure Appl Chem. 2006;78:1455-76.

24. Sabbah R, An XW, Chickos JS, Leitao MLP, Roux MV, Torres LA. Reference materials for calorimetry and differential thermal analysis. Thermochim Acta. 1999;331:93-204.

25. Linksys. Linksys version 2.35. Surrey: Linkam Scientific Instruments; 2000.

26. Andrew ER, Bradbury A, Eades RG. Removal of dipolar broadening of nuclear magnetic resonance spectra of solids by specimen rotation. Nature. 1959;183:1802-3.

27. Andrew ER, Szczesniak E. A historical account of NMR in the solid state. Prog Nucl Magn Reson Spectrosc. 1995;28:11-36.
28. Justino LLJ, Ramos ML, Knaapila M, Marques AT, Kudla C, Scherf U, Almasy L, Schweinz R, Burrows HD, Monkman AP. Gel formation and interpolymer alkyl chain interactions with poly(9,9-dioctylfluorene-2,7-diyl) (PFO) in toluene solution: results from NMR, SANS, DFT, and semiempirical calculations and their implications for PFO beta-phase formation. Macromolecules. 2011;44:334-43.

29. Lowe IJ. Free induction decays of rotating solids. Phys Rev Lett. 1959;2:285-7.

30. Mullin JW. Crystallization. Oxford: Butterworth Heinemann; 1993.

31. Gigante B, Esteves MA, Pires N, Davies ML, Douglas P, Fonseca SM, Burrows HD, Castro RAE, Pina J, de Melo JS. Synthesis, spectroscopy, photophysics and thermal behaviour of stilbenebased triarylamines with dehydroabietic acid methyl ester moieties. New J Chem. 2009;33:877-85.

32. Canotilho J, Castro RAE. The structure of betaxolol studied by infrared spectroscopy and natural bond orbital theory. Spectrochim Acta A. 2010;76:395-400.

33. Maria TMR, Jesus AJL, Eusebio MES. Glass-forming ability of butanediol isomers. J Therm Anal Calorim. 2010;100:385-90. 